\title{
Analysis of Concrete-Filled Square Steel Tube Short Columns under Eccentric Loading
}

\author{
Qifeng Shan, ${ }^{1}$ Jingming Cai ${ }^{D},{ }^{2,3}$ Xiaopeng Li, ${ }^{4}$ and Jiawei $\operatorname{Tan}^{3}$ \\ ${ }^{1}$ Zhejiang Industry Polytechnic College, Shaoxing, China \\ ${ }^{2}$ Key Laboratory of Concrete and Prestressed Concrete Structures of Ministry of Education, Southeast University, Nanjing, China \\ ${ }^{3}$ Department of Civil Engineering, KU Leuven, Belgium \\ ${ }^{4}$ Department of Civil and Environmental Engineering, University of California, Irvine, USA
}

Correspondence should be addressed to Jingming Cai; jingming.cai@kuleuven.be

Received 4 April 2019; Revised 11 May 2019; Accepted 28 May 2019; Published 20 June 2019

Academic Editor: Giovanni Minafò

Copyright (c) 2019 Qifeng Shan et al. This is an open access article distributed under the Creative Commons Attribution License, which permits unrestricted use, distribution, and reproduction in any medium, provided the original work is properly cited.

\begin{abstract}
The concrete-filled square steel tube (CFSST) columns have been widely applied in structural engineering. Although many constitutive models have been proposed to describe CFSST short columns under concentric loading, the applicability of the existing concentric model in the analysis of CFSST short columns under eccentric loading has not been properly verified. In this paper, the eccentric behaviors of CFSST short columns were investigated with the software of ABAQUS/standard. It was found that the contact stress between steel tube and inner concrete was seriously affected by eccentric ratios, indicating that the confinement effect of steel tube on inner concrete was different under concentric and eccentric loading. In this paper, a new stress-strain model of inner concrete which considered the influence of eccentricity was developed and verified with existing experimental results. It was found that the proposed stress-strain model was more accurate in simulating the eccentric behaviors of CFSST short columns.
\end{abstract}

\section{Introduction}

Concrete-filled steel tube (CFST) columns are typical composite members consisting of outer steel tube infilled with inner concrete. The outer steel tube confines the inner concrete, which increases the compressive strength and ductility of CFST columns. The inner concrete forms an ideal core to withstand the compressive loading, and it prevents local buckling of the outer steel tube, particularly in square CFST columns. Numerous tests have illustrated that CFST columns have both higher strength and ductility under compressive loading when compared with traditional steel reinforced concrete columns [1]. In current international practices, CFST columns have been widely applied as vertical loadbearing components in high-rise structures, bridges, and ocean infrastructures [2-5].

In engineering practice, however, it was noticed that CFST columns are inevitably subjected to eccentric compressive loading, although the columns are designed to sustain concentric loading. This may be due to geometric and material imperfections during the manufacturing process, minor misalignment during the construction process, or accidental lateral drift in the service, and so on. Extensive experimental researches have been conducted to investigate the mechanical behaviors of CFST columns under eccentric loading [6-8], concluding that CFST columns exhibited good ductile behavior with a bending failure mode under eccentric loading. Numerical analyses based on finite element method were also performed to simulate the mechanical behavior of CFST short columns under eccentrical compression loading. Wang and Liu [9] investigated the behavior of slender square tubed reinforced concrete short columns subjected to eccentric compression with FEA model. Li and Chen [10] simulated and studied the mechanical behavior of eccentrically loaded high strength concrete-filled high strength square steel tube stub columns. Han et al. [11] established an FEA model to simulate the eccentrical behavior of the CFST columns with gaps. Sheehan et al. [12] developed an FEA model to investigate the mechanical behaviors of concrete-filled elliptical steel hollow sections under eccentric compression. Although many FEA models have been developed to describe CFST columns under concentric loading, the applicability 


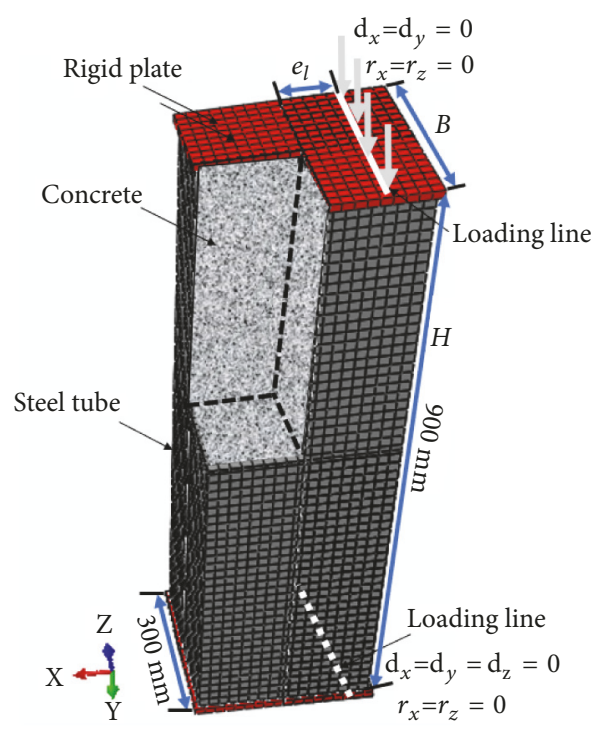

FIGURE 1: FEA model of CFSST columns under eccentric loading.

and accuracy of these FEA models have not been properly verified.

In order to increase the accuracy of FEA models, the constitutive model of inner concrete needs to be carefully considered and established. In above-mentioned studies, the constitutive model proposed by Han et al. [13] was normally adopted to simulate the eccentric behavior of inner concrete. This model considers the confinement effect of steel on inner concrete and the quasi-brittle behavior of inner concrete. Although reasonable predictions have been obtained by some researchers, the applicability and accuracy of this model to simulate the eccentric behavior of inner concrete have not been carefully investigated. In fact, it should be noted that the stress distribution for inner concrete is closely related with the degree of eccentricity, suggesting that the constitutive model needs to consider eccentricity change as a critical parameter. Similar investigations have been conducted for fiber-reinforced polymer- (FRP-) confined concrete columns under eccentric loading by both experimental and analytical methods [14-17]. It has been concluded that eccentrically loaded columns exhibit different mechanical behavior in accordance with different eccentricities. Therefore, the constitutive models for FRP-confined concrete under concentric loading cannot be directly applied and thus new constitutive models have been proposed and verified [18, 19]. Cai et al. investigated the circular concrete-filled steel tube columns under eccentric loading; it was found that the steel tube provided nonuniform confinement stress to inner concrete under eccentric loading [20]. For concrete-filled square steel tube, however, the stress concentration phenomenon was much more evident than circular steel tube, which increased the nonlinearity and complexity for concrete-filled square steel tube columns under eccentric loading.

Set against this background, this paper aimed to investigate the eccentric behavior of concrete-filled square steel tube short columns with different eccentricities. A new constitutive model that considers the influences of eccentricities was proposed. The accuracy of the new constitutive model was verified via comparing with published experimental results.

\section{FEA Modeling}

In order to analyze the influence of eccentricities on the eccentric behavior of the CFSST columns, the FEA model was established as shown in Figure 1. The ratio of length to cross-sectional width for the specimen is three, which can be classified as a typical short column. Two rigid plates with infinite stiffness were attached on the two ends of CFSST column. The interaction between the rigid plate and steel tube was defined as Tie contact; thus the stress could be effectively transferred under eccentric loading. The interactions between rigid palate and inner concrete were defined as hard contact in order to prevent the penetration of the inner concrete into the rigid plate at the constraint locations. The concentric and eccentric loading was applied on the top rigid plate along the loading line. As has been depicted in Figure 1, all the freedom degrees for the loading line were constrained except the displacement along the $\mathrm{Z}$ axis and the rotation around the $\mathrm{Y}$ axis, so that the eccentric load could be applied on the CFSST column. An identical loading line was also attached on the bottom rigid plate to provide the reaction force, in which all the freedom degrees were constrained except the rotation around $\mathrm{Y}$ axis. The interaction between inner concrete and steel tube was defined as contact surfaces, where the Mohr-Coulomb friction model and hard contact model were used to define the contact behaviors in both tangential and normal directions, respectively [21]. All the components, including inner concrete, steel tube, and rigid plate, were modeled using eight-node solid elements with reduced integration (C3D8R).

The five-stage stress-strain model proposed by Han et al. [13] was applied to describe the isotropic elastic-plastic behavior of steel, as shown in (1) and Figure 2. 


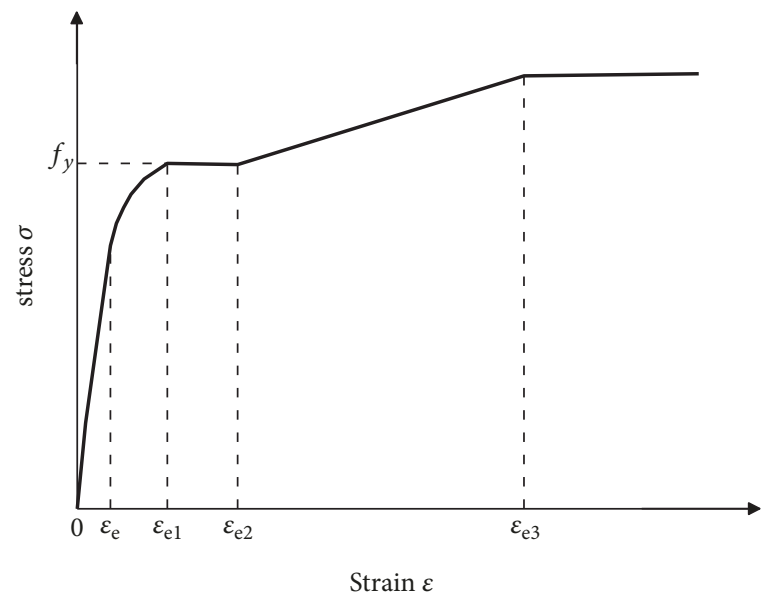

FIGURE 2: Stress-strain model for steel.

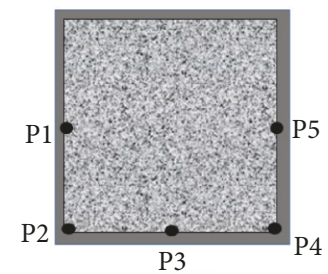

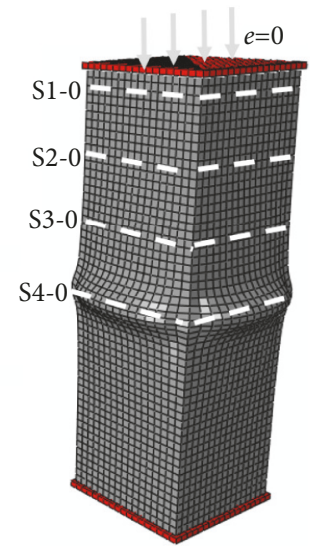

(a)

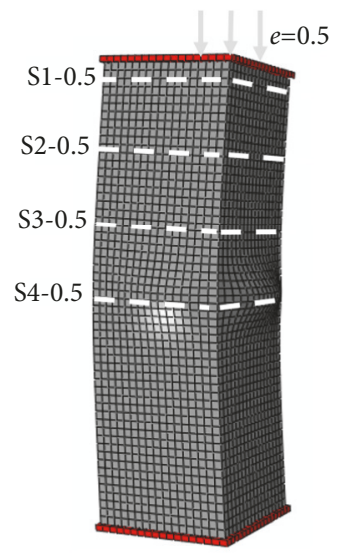

(b)

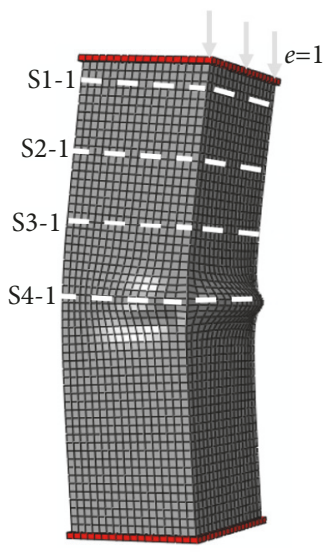

(c)

FIGURE 3: Failure modes for CFSST columns with eccentricity ratios of (a) $e=0$; (b) $e=0.5$; (c) $e=1$.

$$
\sigma_{s}= \begin{cases}\mathrm{E}_{s} \varepsilon_{s} & \varepsilon_{s}<\varepsilon_{e} \\ -A \varepsilon_{s}^{2}+B \varepsilon_{s}+C & \varepsilon_{e}<\varepsilon_{s} \leq \varepsilon_{e 1} \\ f_{y}^{t} & \varepsilon_{e 1}<\varepsilon_{s} \leq \varepsilon_{e 2} \\ f_{y}^{t}\left[1+0.6 \frac{\varepsilon_{s}-\varepsilon_{e 2}}{\varepsilon_{e 3}-\varepsilon_{e 2}}\right] & \varepsilon_{e 2}<\varepsilon_{s} \leq \varepsilon_{e 3} \\ 1.6 f_{y}^{t} & \varepsilon_{s} \varepsilon_{s}>\varepsilon_{e 3}\end{cases}
$$

where $\varepsilon_{e}=0.8 f_{y}^{t} / E_{S}, \quad \varepsilon_{e 1}=1.5 \varepsilon_{e}, \quad \varepsilon_{e 2}=10 \varepsilon_{e 1}, \varepsilon_{e 3}=100 \varepsilon_{e 1}, A=$ $0.2 f_{y}^{t} /\left(\varepsilon_{e 1}-\varepsilon_{e}\right)^{2}, B=2 A \varepsilon_{e 1}$, and $C=0.8 f_{y}+A \varepsilon_{e}^{2}-B \varepsilon_{e}$.

The stress-strain model proposed by Han [13] was also applied to simulate the quasibrittle behavior of inner concrete, which is shown in (2).

$$
y= \begin{cases}2 x-x^{2} & (x \leq 1) \\ \frac{x}{\beta_{0}(x-1)^{1.6+1.5 x}+x} & (x>1)\end{cases}
$$

where $x=\varepsilon / \varepsilon_{0}, y=\sigma / \sigma_{0}, \sigma_{0}=f_{c}^{\prime}, \varepsilon_{0}=\varepsilon_{c}+800 \varepsilon^{0.2} 10^{-6}$, $\varepsilon_{c}=\left(1300+12.5 f_{c}^{\prime}\right) 10^{-6}, \beta_{0}=f_{c}^{\prime 0.1} / 1.2 \sqrt{1+\xi}$, and $\xi=$ $A_{s} f_{y}^{t} / A_{c} f_{c k}$.
The concrete damaged plasticity (CDP) model in ABAQUS was applied to illustrate the plastic behavior of concrete $[22,23]$. In above equations, $A_{s}$ and $A_{c}$ are the cross-sectional area of square steel tube and inner concrete, which were set as $11400 \mathrm{~mm}^{2}$ and $78400 \mathrm{~mm}^{2}$ in this modelling, respectively. The parameters $f_{y}^{t}$ and $f_{c}^{\prime}$ and are the yield strength of steel and cylinder strength of inner concrete, which were set as $340 \mathrm{MPa}$ and $40 \mathrm{MPa}$ in this modelling, respectively. The fracture energy model proposed was used to simulate the tensile softening behavior of concrete [23]. Poisson's ratio and elastic modulus for inner concrete are taken as 0.2 and $4730 \sqrt{f_{c}^{\prime}}$ according to ACI 318-11 [24], respectively.

The typical failure modes for CFSST columns with different eccentric ratios are shown in Figure 3. The eccentric ratio (e) was defined as $e=e_{l} / B$, where $e_{l}$ is the distance from loading line to symmetry axis and $B$ is defined as the half of outside width of square steel tube, as shown in Figure 1. For CFSST column under concentric loading $(e=0)$, as shown in Figure 3(a), an obvious outward local-buckling behavior can be observed in the midsection of steel tube. It should be 
S, Mises

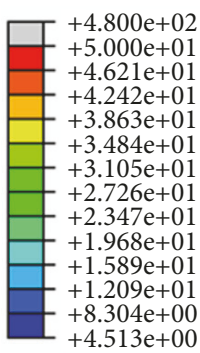

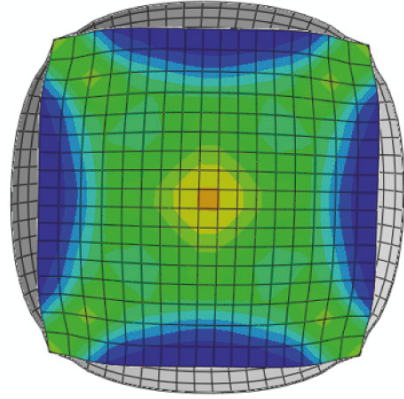

(a)

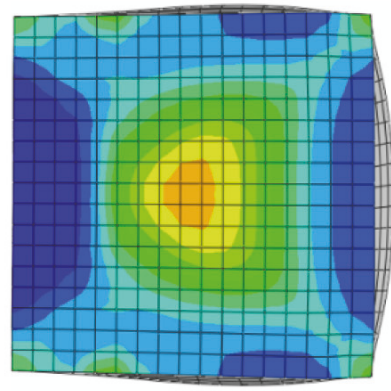

(b)

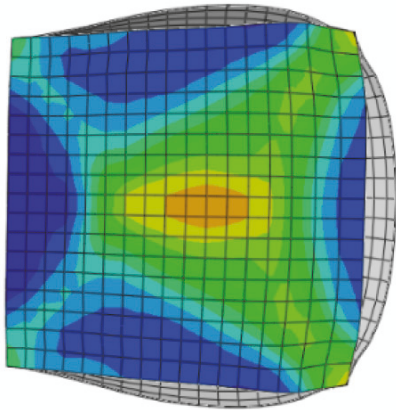

(c)

FIGURE 4: Failure modes for typical sections (a) S4-0; (b) S4-0.5; (c) S4-1.

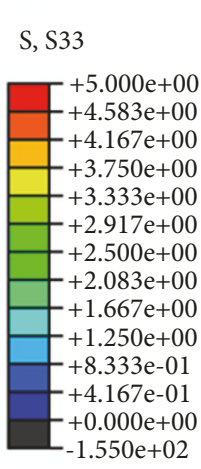

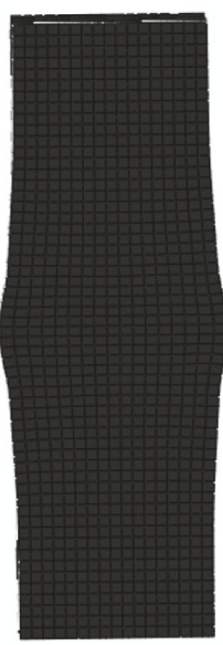

(a)

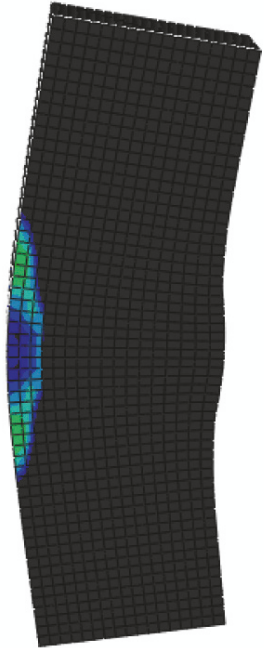

(b)

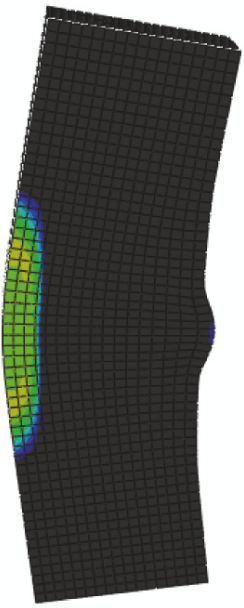

(c)

FIGURE 5: The tensile stress distribution of inner concrete with different eccentrical ratios (a) $e=0$; (b) $e=0.5$; (c) $e=1$.

noted that the outward local-buckling behavior appeared on all the four sides of the square steel tube; thus the specimen showed a drum-like failure mode. For CFSST column with the eccentric ratio of 0.5 , the outward local-buckling behavior can be observed on the compressive side. With the further increase of eccentric ratio, as can be seen in Figure 3(c), the local-buckling behavior was more evident on the compressive side and flank either side, while no buckling behavior was observed on the tensile side. It can be concluded that the CFSST columns have quite different composite behavior between steel tube and inner concrete with different eccentric ratios. Four sections of each column, i.e., S1, S2, S3, and S4, were selected for further analysis as shown in Figure 3. The suffix number for each section, i.e., $0,0.5$, and 1 , represents the eccentric ratio of the column. The midsections for typical CFSST columns, i.e., S4-0, S4-0.5, and S4-1, are shown in Figure 4. For section S4-0, as shown in Figure 4(a), the inner concrete was separated from steel tube except for the corner area and an obvious stress concentration phenomenon can be observed in the corner area from the stress nephogram. For sections S4-0.5 and S4-1, the inner concrete was separated from steel tube mainly in compressive side and flank either side while the steel tube was well contacted with inner concrete in the tensile side. Also, the stress concentration phenomenon for sections S4-0.5 and S4-1was not as severe as section S4-0, indicating the stress distribution was different when the eccentric ratio changed. The stress distribution of inner concrete with different eccentricity ratios is shown in Figure 5, where negative stress represents tension while positive stress represents compression. For CFSST column under concentric loading, all the inner concrete was under compression stress as shown in Figure 5(a). For CFSST column with the eccentric ratio of 0.5, as shown in Figure 5(b), an apparent tensile region appeared in the tensile side. With the increase of eccentric ratio, as shown in Figure 5(c), the tensile region expanded as well. The maximum tensile stress in Figure 5(c) was about $4 \mathrm{MPa}$, indicating that some tensile fractures and cracks may appear on the tensile side of the concrete part.

In order to find the relationship between confinement effect and eccentric ratios, five typical points, i.e., P1, P2, $\mathrm{P} 3$, P4, and P5, for each section were selected, which is 

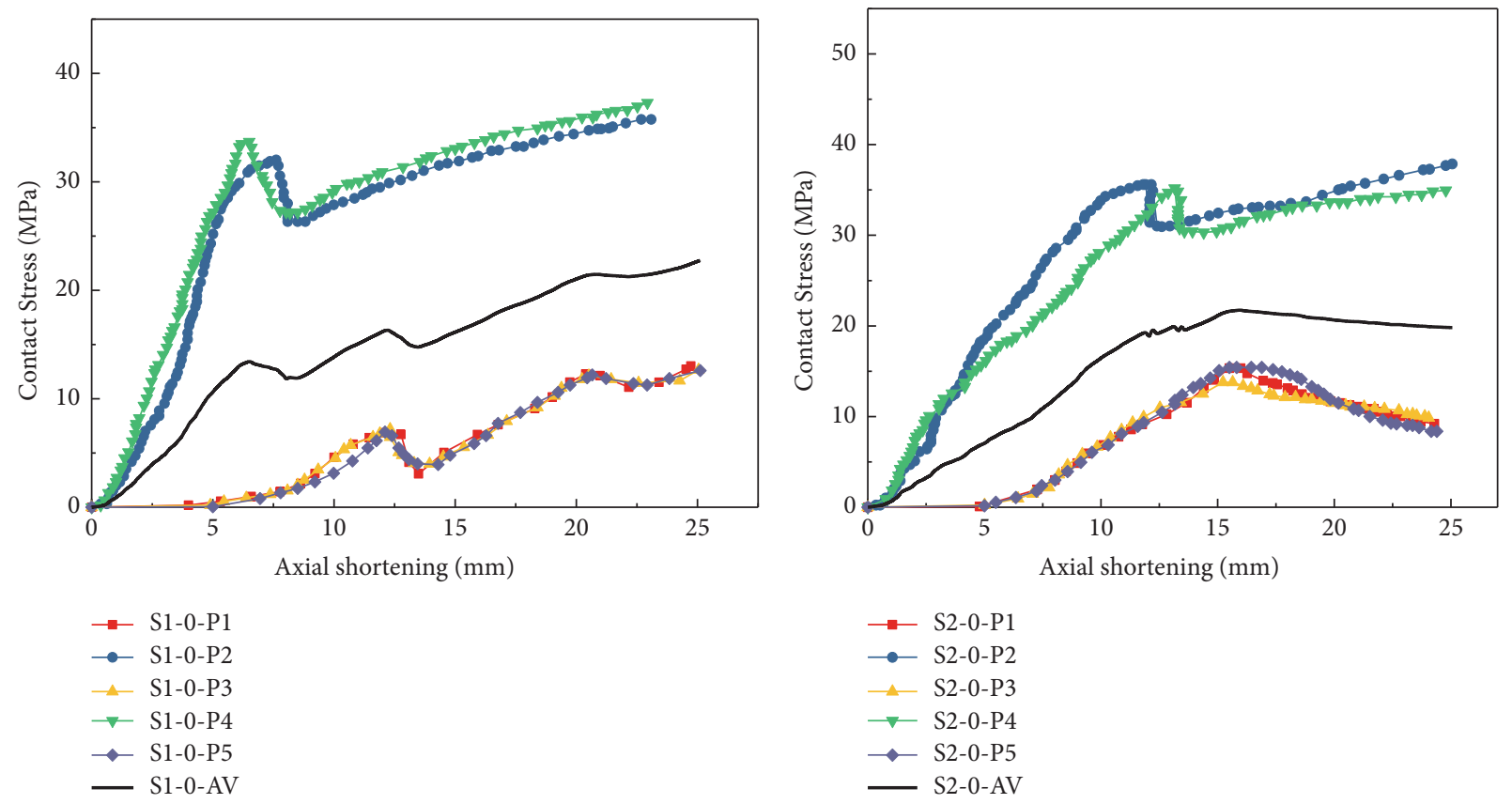

(a) $\mathrm{S1}-0$

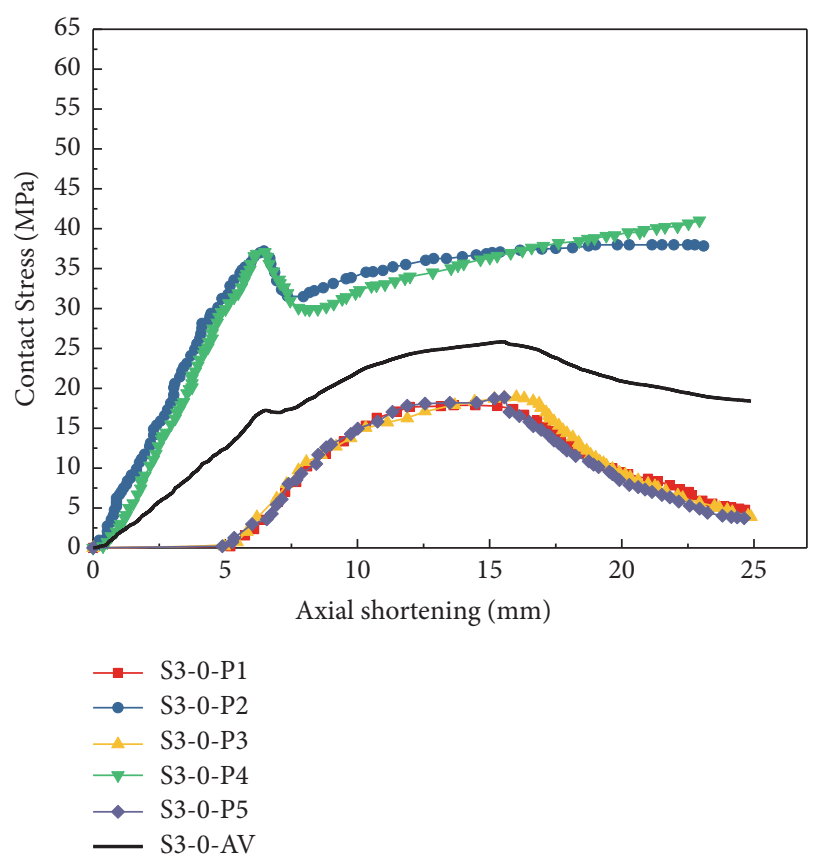

(c) $\mathrm{S} 3-0$

(b) S2-0

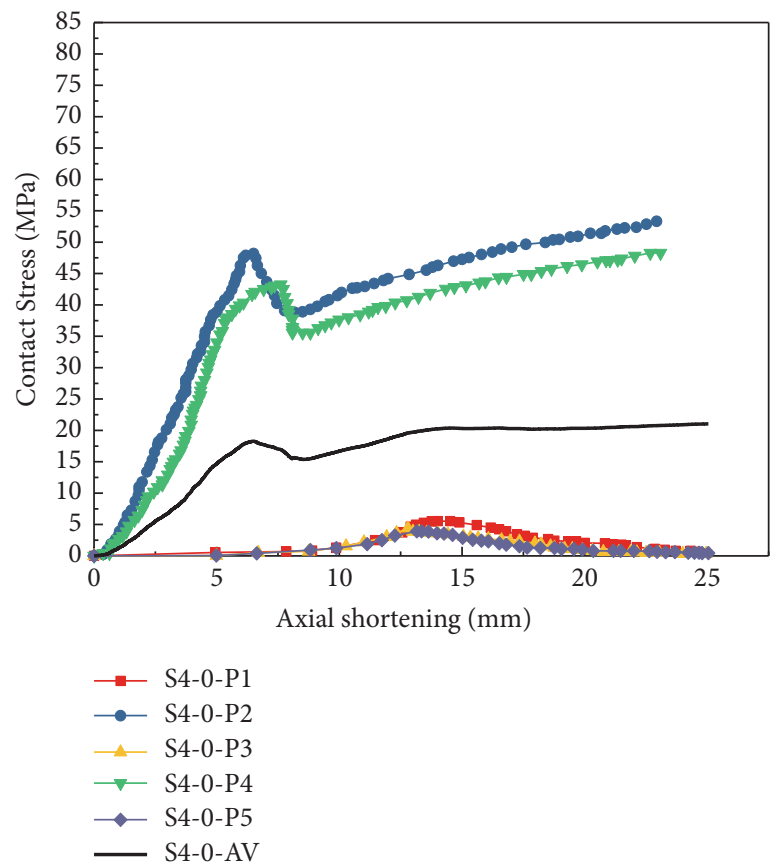

(d) S4-0

FIGURE 6: Contact stress for CFSST columns under axial loading.

shown in Figure 3. The contact stress between steel tube and inner concrete at each point can be obtained with ABAQUS/standard software. The contact stress for CFSST columns with typical eccentric ratios, i.e., $0,0.5$, and 1 , is discussed as follows.

2.1. Concentric Loading $(e=0)$. The contact stress between steel tube and inner concrete for CFSST columns under concentric loading are shown in Figure 6. As the nomenclature for each curve, the first parameter denotes the section, the second parameter denotes the eccentrical ratio, and the third parameter denotes the location of the detected points. It can be seen that the contact stresses are very similar for each section at P1, P3, and P5. By contrast, the contact stress at P2 and P4 is much higher than other detected points. This is reasonable because $\mathrm{P} 2$ and $\mathrm{P} 4$ were located in the cornerangle area; thus the inner concrete was well confined due to stress concentration phenomenon, which is quite different 


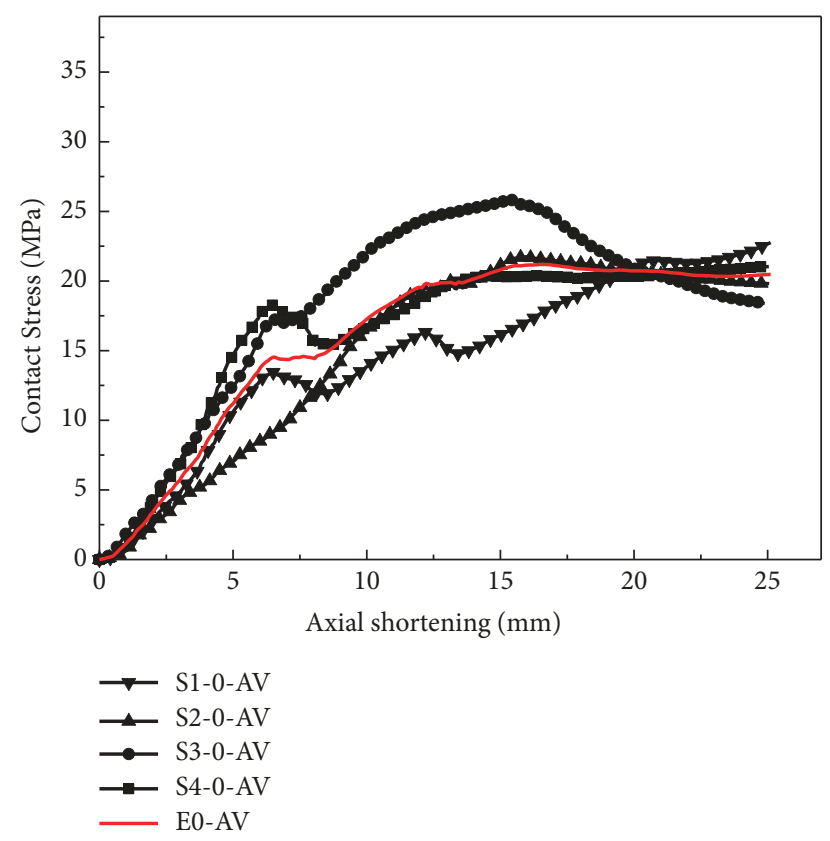

FIgURE 7: Average contact stress for CFSST columns $(e=0)$.

from concrete-filled circular steel tube [20]. It can also be found that the contact stress was fluctuated around zero at the initial stage for P1, P3, and P5, while contact stress increased linearly during the initial stage for P2 and P4.

It can be concluded that the contact stress can be quite different at different regions. In order to simplify the stress distribution, the average curve was also plotted in Figure 6. Considering the symmetry of each section, the contact stress for each section can be represented by the average curve. The average curves for each section are shown in Figure 7; it can be seen that the distribution of stress was also nonuniform along the axial direction of the CFSST column. Thus, an average curve for each section, curve E0-AV, was also plotted in Figure 7.

2.2. Eccentric Loading ( $e=0.5$ and 1 ). The contact stress for CFSST columns under eccentric loading is shown in Figure 8. With the increase of eccentrical ratio, the contact stress decreased significantly, indicating that the confinement effect was weakened as well. It can be found that the contact stress at $\mathrm{P} 2$ and $\mathrm{P} 4$ is much higher than $\mathrm{P} 1, \mathrm{P} 3$, and $\mathrm{P} 5$, which is due to the stress concentration phenomenon in the cornerangle area as well. Also, it can be seen that the contact stress distributed nonuniformly in P1, P3, and P5, indicating the eccentric loading has a great impact on the distribution of stress on the sections. Taking curve S4-0.5-P5 as an example, the contact stress fluctuated around zero during the initial stage, suggesting that the inner concrete was separated from the steel tube due to the different Poisson's ratios of the concrete and the steel. With increasing axial displacement, the contact stress in S4-0.5-P5 increased slowly because the inner concrete was crushed and contacted with steel tube in this stage. With the further increase of eccentric loading, the contact stress in S4-0.5-P5 decreased rapidly and fluctuated around zero again during the last stage. This is attributed to the outward local buckling in the compressive side of steel tube, leading to the gradual separation between the inner concrete and the steel tube in this stage.

The average contact stresses for CFSST columns under eccentric loading are shown in Figure 9. The contact stress for CFSST columns with the eccentrical ratios of 0.5 and 1 was represented by curves E0.5-AV and E1-AV, respectively. It can be seen that the contact stress decreased with the increase of eccentric ratios.

2.3. New Stress-Strain Model for Core Concrete. The average contact stress for columns with different eccentric ratios, i.e., 0, 0.5, and 1, is shown in Figure 10. It is evident that the contact stress decreased rapidly with the increase of eccentric ratios; thus the influence of eccentric ratios should be considered in the stress-strain model. A new parameter $k$, which represents the influence of eccentric loading, was proposed as follows:

$$
\begin{aligned}
S_{i} & =\int_{0}^{d_{u}} \sigma\left(\varepsilon_{i}\right) \mathrm{d} \varepsilon \\
k & =\frac{S_{i}}{S_{0}}
\end{aligned}
$$

where $S_{i}$ represents the area under the contact stress curves for CFSST columns with different eccentrical ratios. The confinement coefficient $(k)$ at different eccentric ratios $r$ could be obtained according to (3) and (4), which is shown in Figure 10.

As shown in Figure 11, the confinement coefficient decreased with the increase of eccentric ratios, which is consistent with the previous discussions. With the nonlinear fitting approach, the confinement coefficient $(k)$ can be expressed as follows.

$$
k=0.59 \exp \left(-\frac{e}{0.44}\right)+0.42
$$

where $k$ is confinement coefficient and $e$ is the eccentric ratio of CFSST columns.

Based on the stress-strain model proposed by Tao et al. [24], a new three-stage constitutive model which considered the influence of eccentric loading was proposed. During the initial stage, steel tube has negligible confinement for inner concrete. Therefore, the stress-strain relationship for confined concrete during the initial stage is linear and no confinement effect or eccentric ratios were considered in this stage, which was given by:

$$
\frac{\sigma}{f_{c}^{\prime}}=\frac{A X+B X^{2}}{1+(A-2) X+(B-1) X^{2}} \quad 0<\varepsilon \leq \varepsilon_{c 0}
$$

where $\mathrm{X}=\varepsilon / \varepsilon_{c 0} ; \mathrm{A}=E_{c} \varepsilon_{c 0} / f_{c}^{\prime} ; \mathrm{B}=\left(A-1^{2}\right) / 0.55-1 ; \varepsilon_{c 0}=$ $0.00076+\sqrt{\left(0.626 f_{c}^{\prime}-4.33\right) \times 10^{-7}}$.

With the increase of axial deformation, the concrete was gradually cursed and contacted with the steel tube; thus the confinement effect should be considered in this stage. However, the eccentricity also has an important influence on the stress distribution of CFSST columns; the confinement effect was weakened with the increase of eccentrical ratios. 

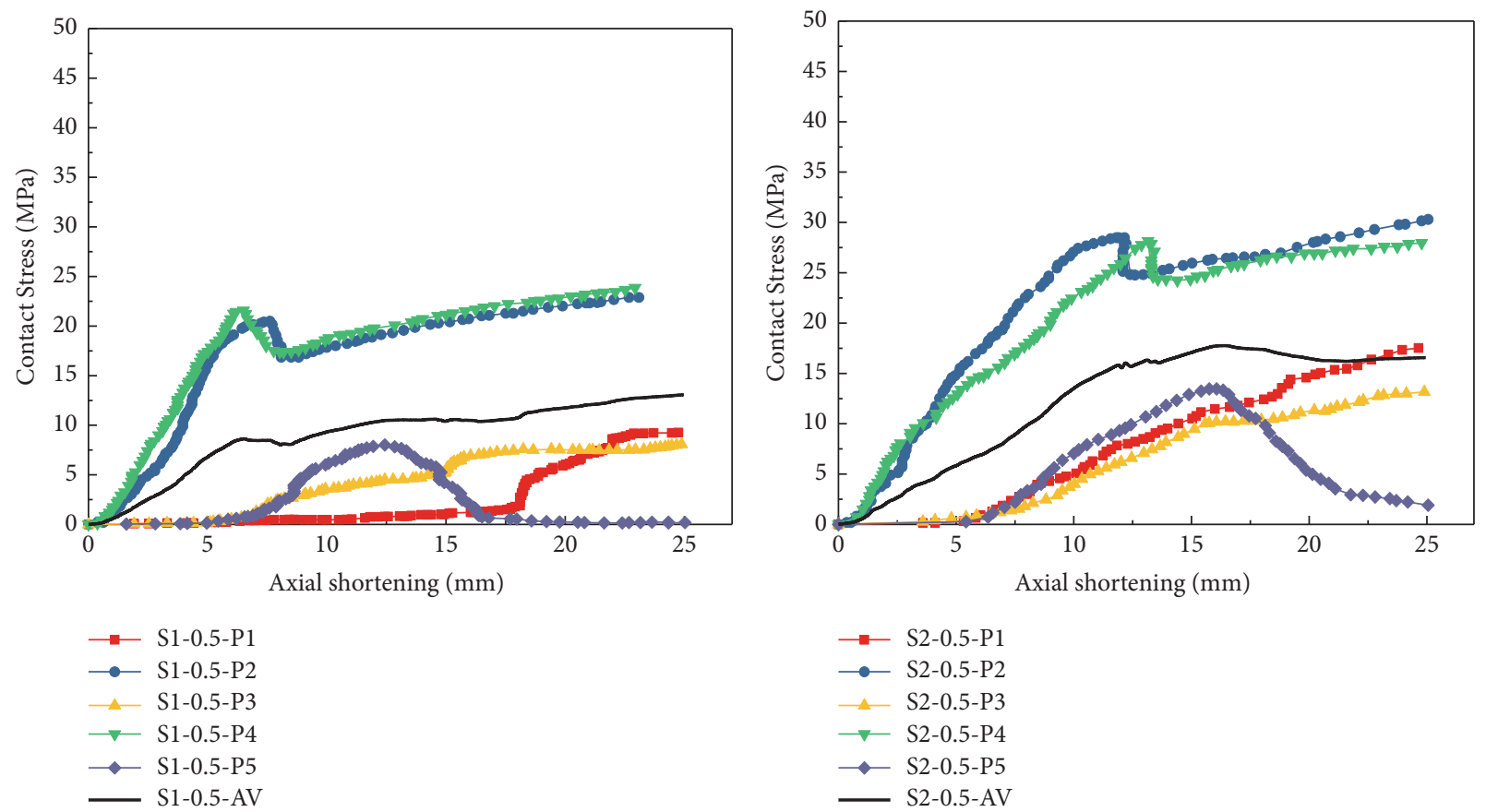

(a) $\mathrm{S} 1-0.5$
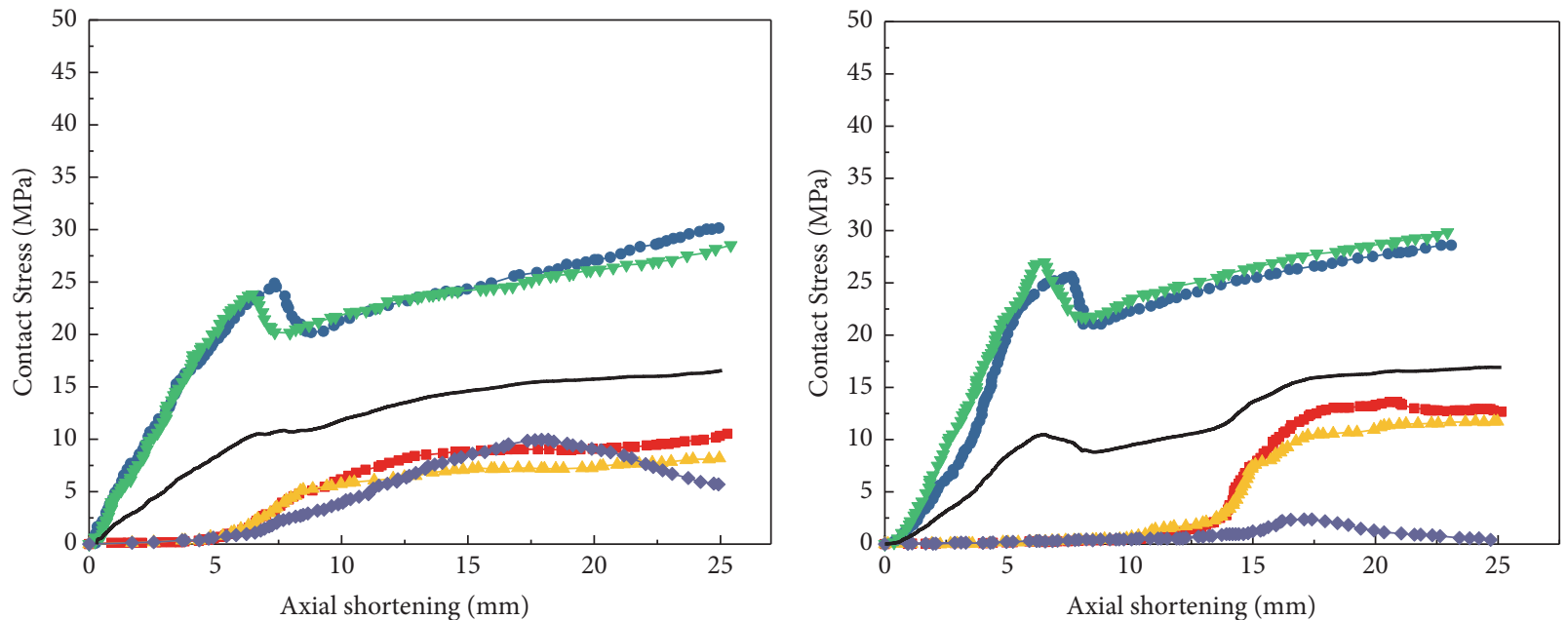

$$
\begin{aligned}
& \rightarrow \text { S3-0.5-P1 } \\
& \rightarrow \text { S3-0.5-P2 } \\
& \multimap \text { S3-0.5-P3 } \\
& \rightarrow \text { S3-0.5-P4 } \\
& \longrightarrow \text { S3-0.5-P5 } \\
& \longrightarrow \text { S3-0.5-AV }
\end{aligned}
$$

(c) $\mathrm{S} 3-0.5$

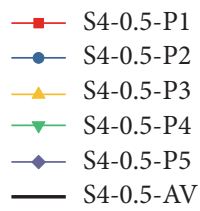

FIgURE 8: Contact stress for CFSST columns under eccentric loading $(e=0.5)$.

During the second stage, a plateau was proposed which is shown as follows:

$$
\frac{\varepsilon_{c c}}{\varepsilon_{c 0}}=e^{m} \quad \varepsilon_{c 0}<\varepsilon \leq \varepsilon_{c c}
$$

where $m=\left(2.9224-0.00367 f_{c}^{\prime}\right)\left(f_{B} / f_{c}^{\prime}\right)^{0.3124+0.002 f_{c}^{\prime}} ; f_{\mathrm{B}}=$ $0.25 k\left(1+0.027 f_{y}\right) \exp ^{-0.028 \mathrm{~B} / \mathrm{t}} /\left(1+1.6 * 10^{-10}\left(f_{c}^{\prime}\right)^{4.8}\right) ; k=$ $0.59 \exp (-\mathrm{e} / 0.44)+0.42$.
During the third stage, both the confinement effect and eccentrical ratios should be considered in the stress-strain model, which is shown as follows:

$$
\sigma=f_{r}+\left(f_{c}^{\prime}-f_{r}\right) \exp \left[-\left(\frac{\varepsilon-\varepsilon_{c c}}{\alpha}\right)^{1.2}\right] \quad \varepsilon \geq \varepsilon_{c c}
$$

where $f_{r}=0.1 k f_{c}^{\prime} ; \alpha=0.005+\xi_{c} ; \xi_{c}=A_{s} f_{y} / A_{c} f_{c k} ; k=$ $0.59 \exp (-\mathrm{e} / 0.44)+0.42$. 


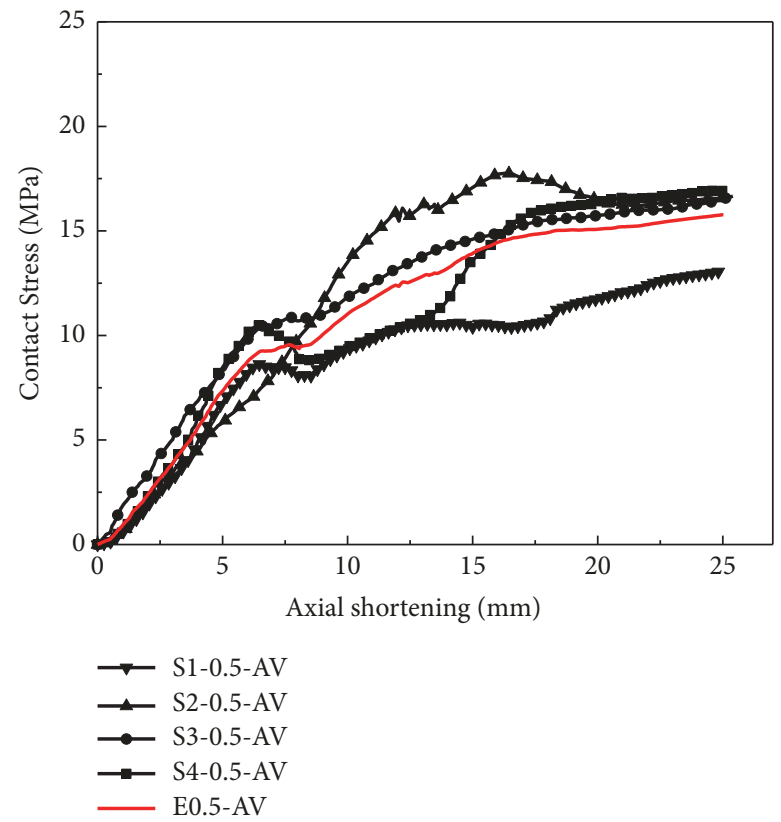

(a) $\mathrm{e}=0.5$

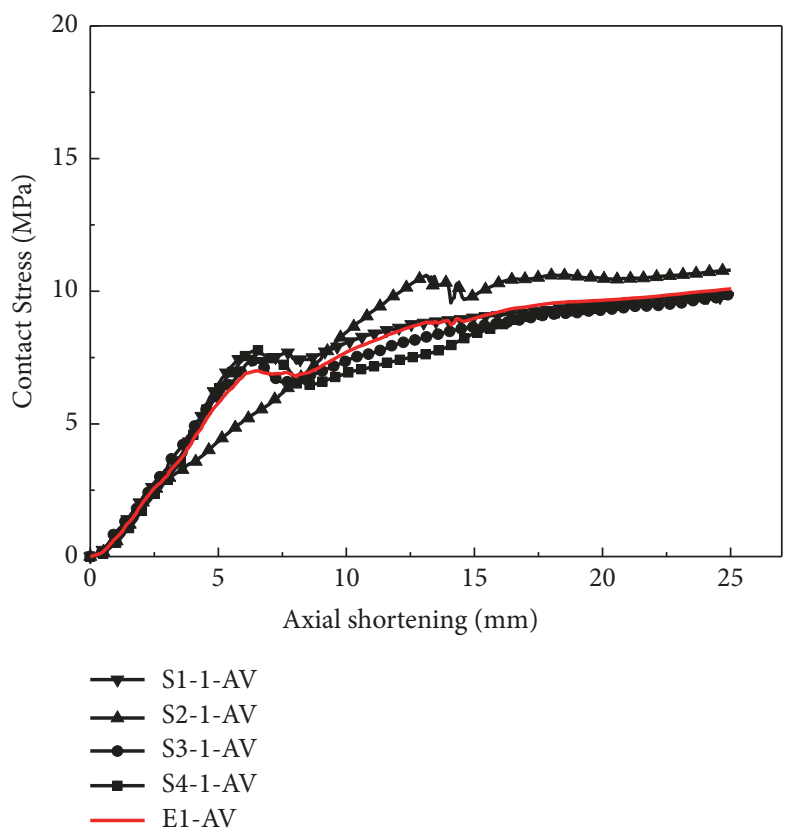

(b) $e=1$

FIGURE 9: Average contact stress for CFSST columns under eccentric loading.

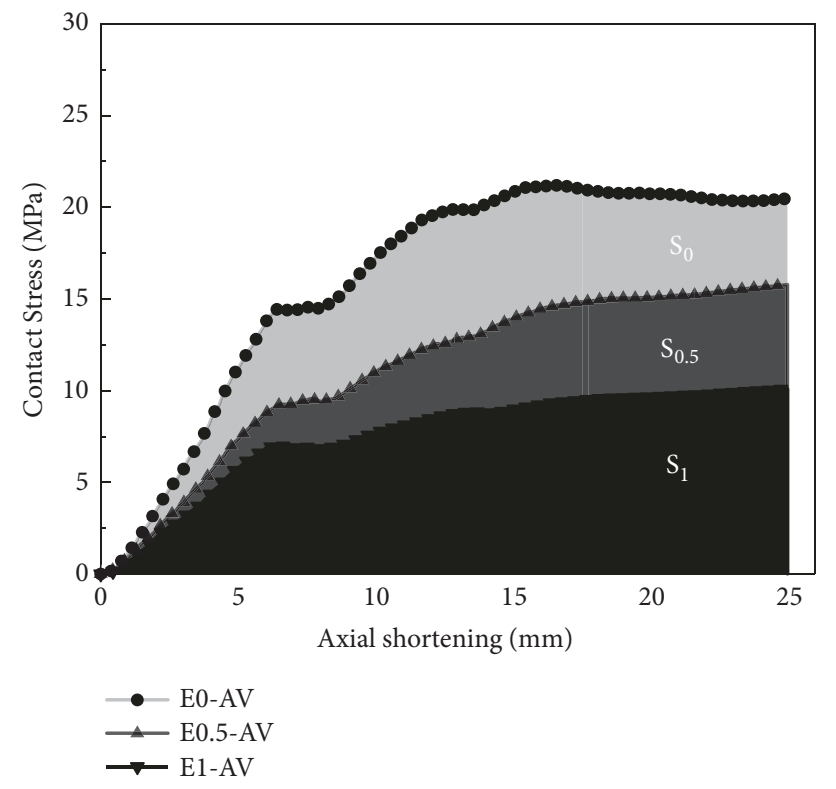

FIgURE 10: Area enclosed by the stress-strain curves and the horizontal axis.

\section{Validation of the Proposed Constitutive Model}

In order to validate the stress-strain model for CFSST columns under eccentric loading, the simulation results were compared with the experimental results from different references, as shown in Figure 12. Both Han's model and the current proposed model were used to model the mechanical behavior of inner concrete. During the initial stage, both Han's model and the current model gave an accurate prediction. With the increase of axial deformation, the current model was more accurate, especially during the strain-softening stage.

The carrying capacities for CFSST columns are shown in Table 1, in which $P_{\text {test }}$ and $P_{F E}$ are the peak load derived from experiment and FEA model with current proposed stress-strain model, respectively. It can be seen that a good prediction could be achieved and the average variation between predicted and experimental results is below $5 \%$. Thus, it can be concluded that the model proposed in this 


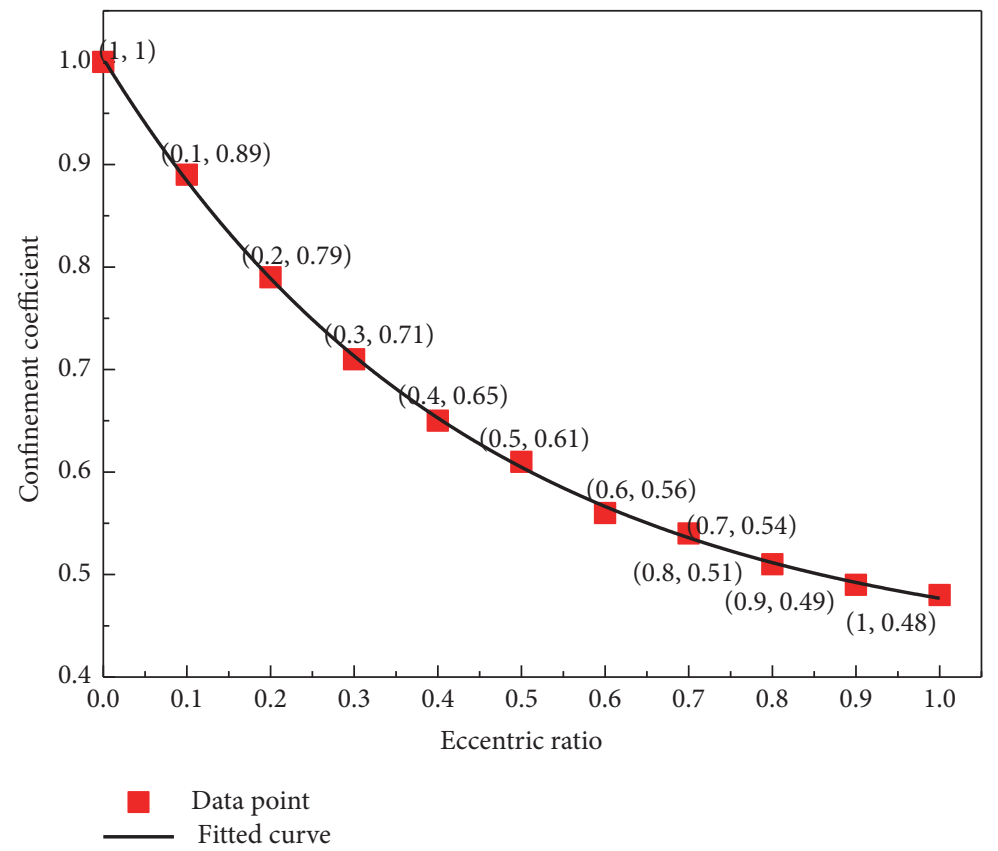

FIGURE 11: The confinement coefficient $(k)$ for CFSST columns under eccentric loading.

TABLE 1: Comparisons between experimental and simulational results.

\begin{tabular}{|c|c|c|c|c|c|c|c|c|}
\hline Ref. & Specimen & $t(\mathrm{~mm})$ & $f_{y}^{t}(\mathrm{MPa})$ & $f_{c}(\mathrm{MPa})$ & $D_{e}(\mathrm{~mm})$ & $P_{\text {test }}(\mathrm{kN})$ & $P_{F E}(\mathrm{kN})$ & $P_{F E} / P_{\text {test }}$ \\
\hline \multirow{17}{*}{ [25] } & HS1C40SA-0.2 & 5.7 & 514.5 & 43.2 & 10.50 & 1440 & 1397 & 0.97 \\
\hline & HS1C40SB-0.2 & 5.7 & 514.5 & 43.2 & 22.00 & 2085 & 1793 & 0.86 \\
\hline & HS1C40SB- 0.2 & 5.7 & 514.5 & 43.2 & 23.25 & 2550 & 2499 & 0.98 \\
\hline & HS1C50SA-0.2 & 5.7 & 514.5 & 55.3 & 13.00 & 1380 & 1408 & 1.02 \\
\hline & HS1C50SB-0.2 & 5.7 & 514.5 & 55.3 & 19.00 & 2140 & 2012 & 0.94 \\
\hline & HS1C50SE- 0.2 & 5.7 & 514.5 & 55.3 & 34.50 & 2470 & 2346 & 0.95 \\
\hline & HS1C40SA-0.4 & 5.7 & 514.5 & 43.2 & 26.50 & 1190 & 1083 & 0.91 \\
\hline & HS1C40SB-0.4 & 5.7 & 514.5 & 43.2 & 38.00 & 1620 & 1669 & 1.03 \\
\hline & HS1C40SE-0.4 & 5.7 & 514.5 & 43.2 & 49.75 & 2150 & 2171 & 1.01 \\
\hline & HS1C50SA-0.4 & 5.7 & 514.5 & 55.3 & 24.50 & 1220 & 1159 & 0.95 \\
\hline & HS1C50SE- 0.4 & 5.7 & 514.5 & 55.3 & 47.75 & 2250 & 2295 & 1.02 \\
\hline & HS1C40SA-0.6 & 5.7 & 514.5 & 43.2 & 35.00 & 1110 & 988 & 0.89 \\
\hline & HS1C40SB-0.6 & 5.7 & 514.5 & 43.2 & 55.50 & 1500 & 1530 & 1.02 \\
\hline & HS1C40SE-0.6 & 5.7 & 514.5 & 43.2 & 74.00 & 1700 & 1632 & 0.96 \\
\hline & HS1C50SA-0.6 & 5.7 & 514.5 & 55.3 & 55.00 & 1020 & 1081 & 1.06 \\
\hline & Mean & & & & & & & 0.971 \\
\hline & \multicolumn{2}{|c|}{ Standard Deviation } & & & & & & 0.054 \\
\hline \multirow{8}{*}{ [10] } & EC1-2 & 4 & 434.56 & 110.5 & 20 & 2129.7 & 1980 & 0.93 \\
\hline & EC2-2 & 4 & 434.56 & 110.5 & 35 & 1717.2 & 1528 & 0.89 \\
\hline & EC3-2 & 4 & 434.56 & 110.5 & 50 & 1454.9 & 1484 & 1.02 \\
\hline & EC4-2 & 4 & 434.56 & 110.5 & 65 & 1244.1 & 1169 & 0.94 \\
\hline & EC5-2 & 5 & 433.10 & 110.5 & 50 & 1630.1 & 1597 & 0.98 \\
\hline & EC6-2 & 6 & 436.90 & 110.5 & 50 & 1797.2 & 1707 & 0.95 \\
\hline & Mean & & & & & & & 0.951 \\
\hline & \multicolumn{2}{|c|}{ Standard deviation } & & & & & & 0.041 \\
\hline
\end{tabular}




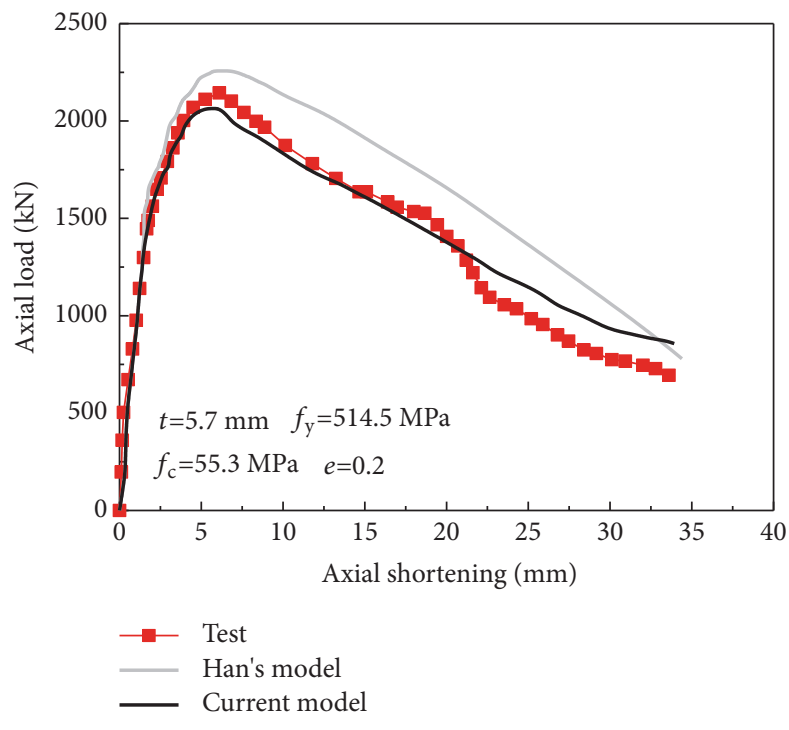

(1)HS1C50SB-0.2[25]

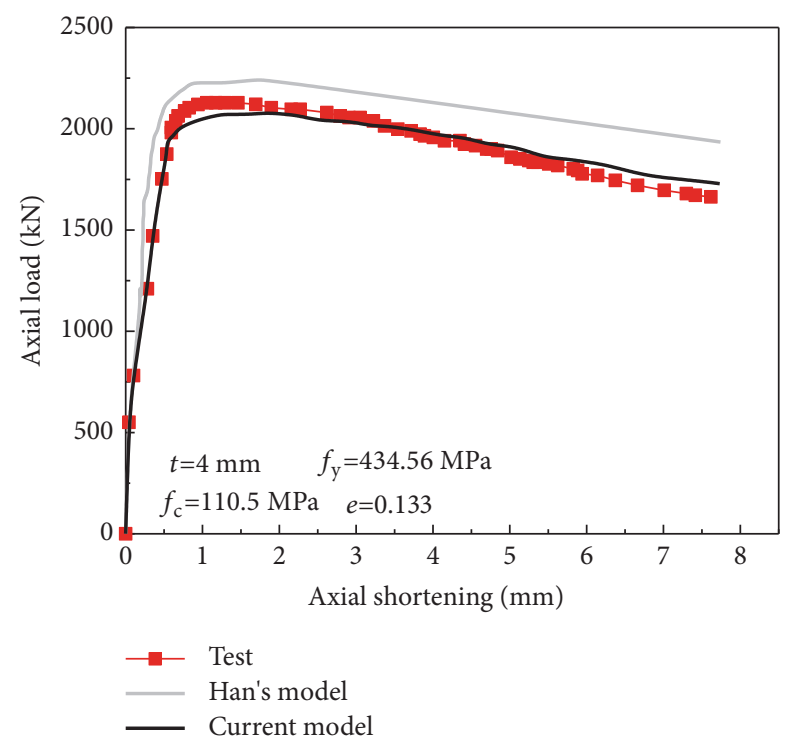

(3)EC1-2[10]

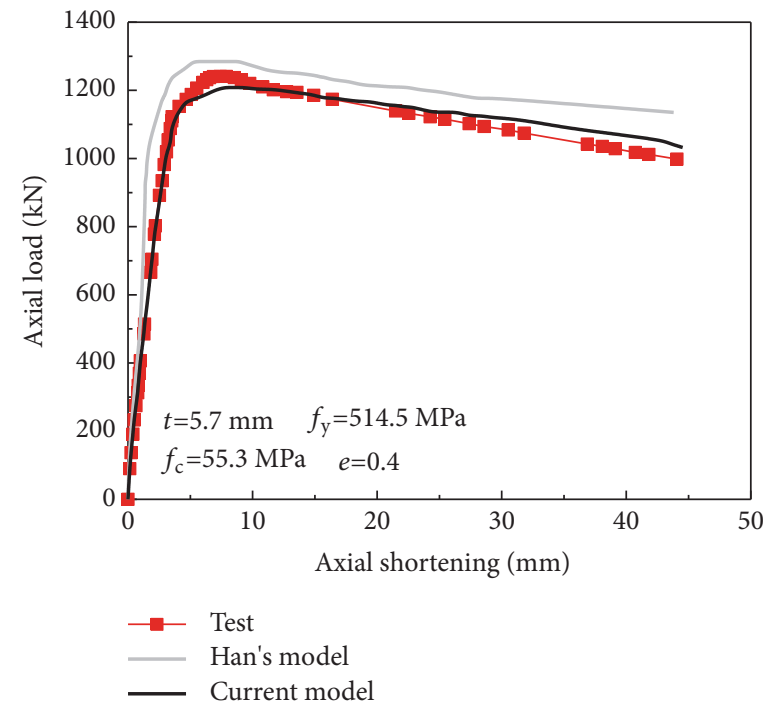

(2)HS1C50SA-0.4[25]

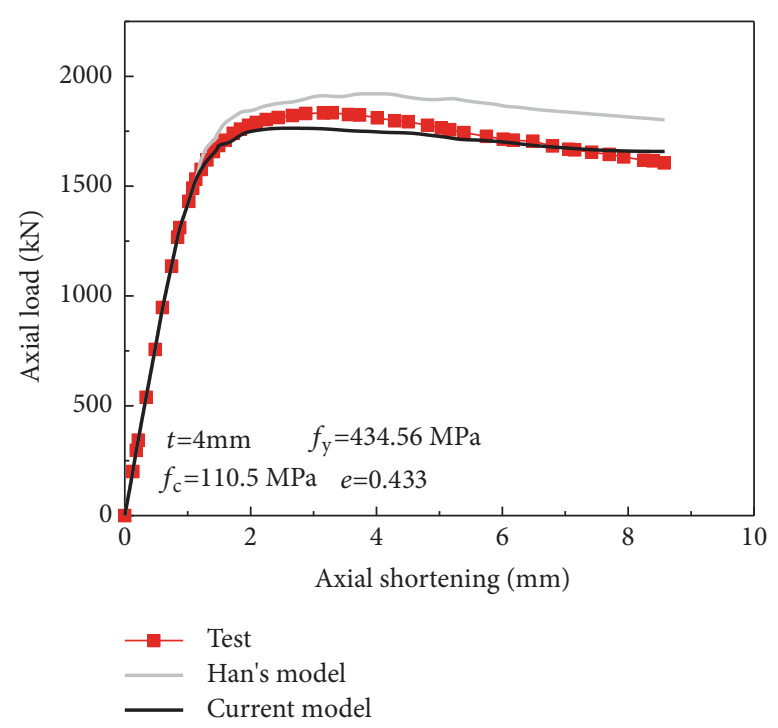

(4)EC4-2[10]

FIGURE 12: Comparisons between experimental and simulational result.

paper is accurate in simulating the eccentric behavior of CFSST columns.

\section{Conclusions}

This paper numerically investigated the eccentric behavior of CFSST columns. The finite element analysis found that the confinement effect of steel tube on concrete was seriously weakened with the increasing of eccentricities. Therefore, existing models tended to overestimate the mechanical behavior of CFSST columns and were not applicable when the CFSST columns were under eccentric loading. This paper proposed a new stress-strain model of CFSST, introducing a new parameter to consider the influence of eccentricity on the confinement effect. Comparisons between simulational results and experimental results from different sources validated the accuracy; the proposed model has a higher applicability to simulate the eccentric behavior of CFSST columns, especially during the strain-softening stage.

\section{Nomenclature}

$A_{c}$ : Cross-sectional area of concrete

$A_{s}$ : Cross-sectional area of the steel tube

$\mathrm{D}_{e}$ : Eccentric distance

$E_{C}$ : Elastic modulus of concrete

$E_{S}$ : Elastic modulus of steel

$e:$ Eccentrical ratio

$f_{c}^{\prime}$ : Cylinder strength of the concrete 
$f_{c k}$ : Characteristic strength of the concrete

$f_{c}$ : Cube compressive strength of concrete

$f_{y}$ : Nominal yield strength of steel

$f_{y}^{t}$ : Yield strength of the steel

$k$ : Confinement coefficient

$N_{u}$ : Load carrying capacity

$M_{\mathcal{u}}$ : Moment carrying capacity

$P_{F E}$ : Peak load recorded from FEA

$P_{\text {test }}$ : Peak load recorded from experiment

$t$ : Wall thickness of the steel tube of CFSST

$\alpha_{s}$ : Steel ratio of steel tube $\left(=A_{s} / A_{c}\right)$

$\varepsilon: \quad$ Strain

$\sigma: \quad$ Stress

$\xi_{c}: \quad$ Confinement factor of CFST $\left(=A_{s} f_{y}^{t} / A_{c} f_{c k}\right)$.

\section{Data Availability}

The data used to support the findings of this study are available from the corresponding author upon request.

\section{Conflicts of Interest}

The authors declare that they have no conflicts of interest.

\section{Acknowledgments}

This work was financially supported by the Open Foundation of Key Laboratory of Concrete and Prestressed Concrete Structure of Ministry of Education under CPCSME201806 and the Fundamental Research Funds for the Central Universities under 3205009601.

\section{References}

[1] L.-H. Han, W. Li, and R. Bjorhovde, "Developments and advanced applications of concrete-filled steel tubular (CFST) structures: members," Journal of Constructional Steel Research, vol. 100, pp. 211-228, 2014.

[2] Y. Huang, Y. Sun, H. Sun, and Q. Wang, "Theoretical analysis on mechanical behavior of axially loaded recycled aggregate concrete filled steel tubes," Mathematical Problems in Engineering, vol. 2015, Article ID 270469, 14 pages, 2015.

[3] J. Ma, Y. Liu, Q. I. Gao, and K. Hou, "Investigating the hysteretic behavior of concrete-filled steel tube arch by using a fiber beam element," Mathematical Problems in Engineering, vol. 2015, Article ID 409530, 7 pages, 2015.

[4] M. T. Stephens, D. E. Lehman, and C. W. Roeder, "Seismic performance modeling of concrete-filled steel tube bridges: Tools and case study," Engineering Structures, vol. 165, pp. 88105, 2018.

[5] Q. Zhou, H. Fu, F. Ding et al., "Seismic behavior of a new through-core connection between concrete-filled steel tubular column and composite beam," Journal of Constructional Steel Research, vol. 155, pp. 107-120, 2019.

[6] T. Fujimoto, A. Mukai, I. Nishiyama, and K. Sakino, "Behavior of eccentrically loaded concrete-filled steel tubular columns," Journal of Structural Engineering, vol. 130, no. 2, pp. 203-212, 2004.
[7] D. Liu, "Behaviour of high strength rectangular concrete-filled steel hollow section columns under eccentric loading," ThinWalled Structures, vol. 42, no. 12, pp. 1631-1644, 2004.

[8] Y.-F. Yang and L.-H. Han, "Behaviour of concrete filled steel tubular (CFST) stub columns under eccentric partial compression," Thin-Walled Structures, vol. 49, no. 2, pp. 379-395, 2011.

[9] X. Wang and J. Liu, "Behavior and design of slender square tubed-reinforced-concrete columns subjected to eccentric compression," Thin-Walled Structures, vol. 120, pp. 153-160, 2017.

[10] G. Li, B. Chen, Z. Yang, and Y. Feng, "Experimental and numerical behaviour of eccentrically loaded high strength concrete filled high strength square steel tube stub columns," Thin-Walled Structures, vol. 127, pp. 483-499, 2018.

[11] L. Han, Y. Ye, and F. Liao, "Effects of Core Concrete Initial Imperfection on Performance of Eccentrically Loaded CFST Columns," Journal of Structural Engineering, vol. 142, no. 12, pp. 1-13, 2016.

[12] T. Sheehan, X. H. Dai, T. M. Chan, and D. Lam, "Structural response of concrete-filled elliptical steel hollow sections under eccentric compression," Engineering Structures, vol. 45, pp. 314$323,2012$.

[13] L.-H. Han, G.-H. Yao, and Z. Tao, "Performance of concretefilled thin-walled steel tubes under pure torsion," Thin-Walled Structures, vol. 45, no. 1, pp. 24-36, 2007.

[14] M. N. S. Hadi and I. B. R. Widiarsa, "Axial and flexural performance of square RC columns wrapped with CFRP under eccentric loading," Journal of Composites for Construction, vol. 16, no. 6, pp. 640-649, 2012.

[15] L. H. Xu, Z. X. Li, and Y. Lv, "Numerical study on nonlinear semiactive control of steel-concrete hybrid structures using MR dampers," Mathematical Problems in Engineering, vol. 2013, Article ID 401410, 9 pages, 2013.

[16] L. Bisby and M. Ranger, "Axial-flexural interaction in circular FRP-confined reinforced concrete columns," Construction and Building Materials, vol. 24, no. 9, pp. 1672-1681, 2010.

[17] X. Fan and M. Zhang, "Behaviour of inorganic polymer concrete columns reinforced with basalt FRP bars under eccentric compression: An experimental study," Composites Part B: Engineering, vol. 104, pp. 44-56, 2016.

[18] M. Z. Kabir and E. Shafei, "Plasticity modeling of FRP-confined circular reinforced concrete columns subjected to eccentric axial loading," Composites Part B: Engineering, vol. 43, no. 8, pp. 3497-3506, 2012.

[19] G. Lin and J. G. Teng, “Three-dimensional finite-element analysis of FRP-confined circular concrete columns under eccentric loading," Journal of Composites for Construction, vol. 21, no. 4, pp. 1-12, 2017.

[20] J. M. Cai and J. L. Pan, "Nonlinear analysis of circular concretefilled steel tube columns under eccentric loading," Magazine of Concrete Research, vol. 71, no. 23, pp. 1-12, 2018.

[21] D. J. Robert, "A modified mohr-coulomb model to simulate the behavior of pipelines in unsaturated soils," Computers \& Geosciences, vol. 91, pp. 146-160, 2017.

[22] M. F. Ferrotto, L. Cavaleri, and F. Di Trapani, "FE modeling of Partially Steel-Jacketed (PSJ) RC columns using CDP model," Computers and Concrete, vol. 22, no. 2, pp. 143-152, 2018.

[23] M. F. Ferrotto, O. Fischer, and L. Cavaleri, "A strategy for the finite element modeling of FRP-confined concrete columns subjected to preload," Engineering Structures, vol. 173, pp. 10541067, 2018. 
[24] A. A. C. I. Standard, Building Code Requirements for Structural Concrete (ACI 318-11), American Concrete Institute, 2011.

[25] Y. Du, Z. Chen, J. Y. Richard Liew, and M.-X. Xiong, "Rectangular concrete-filled steel tubular beam-columns using highstrength steel: Experiments and design," Journal of Constructional Steel Research, vol. 131, pp. 1-18, 2017. 


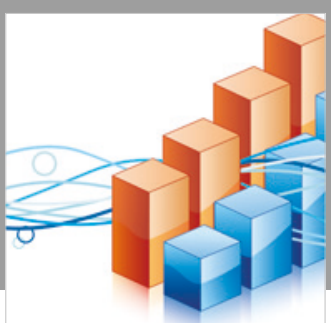

Advances in

Operations Research

\section{-n-m}
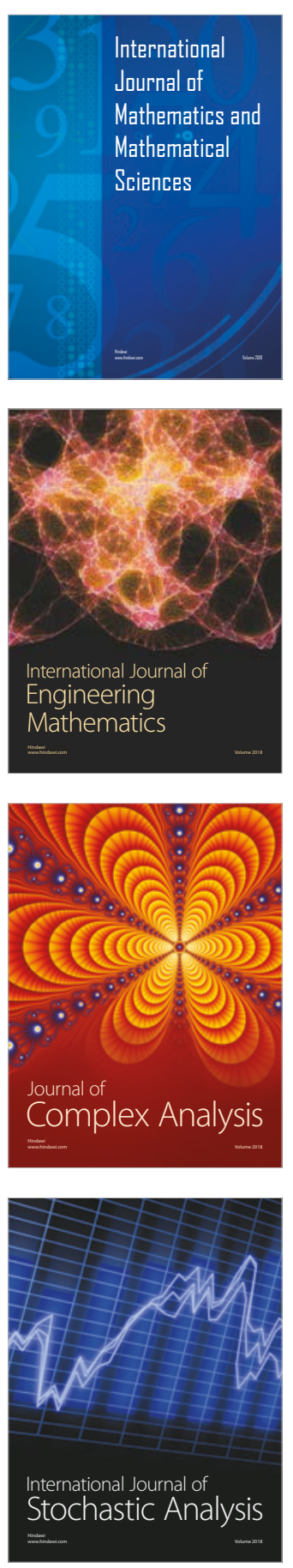
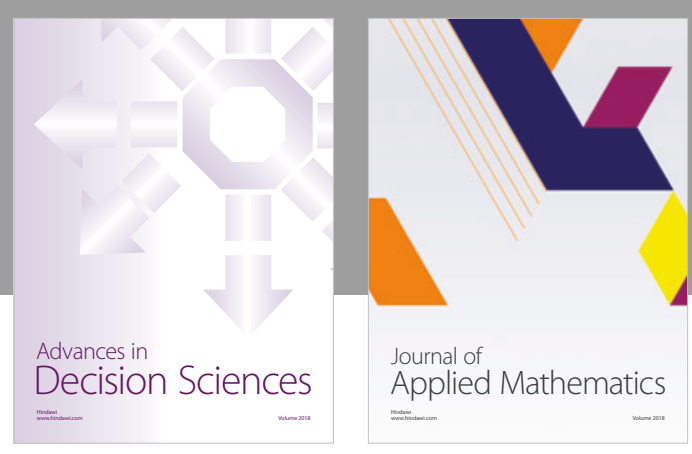

Journal of

Applied Mathematics
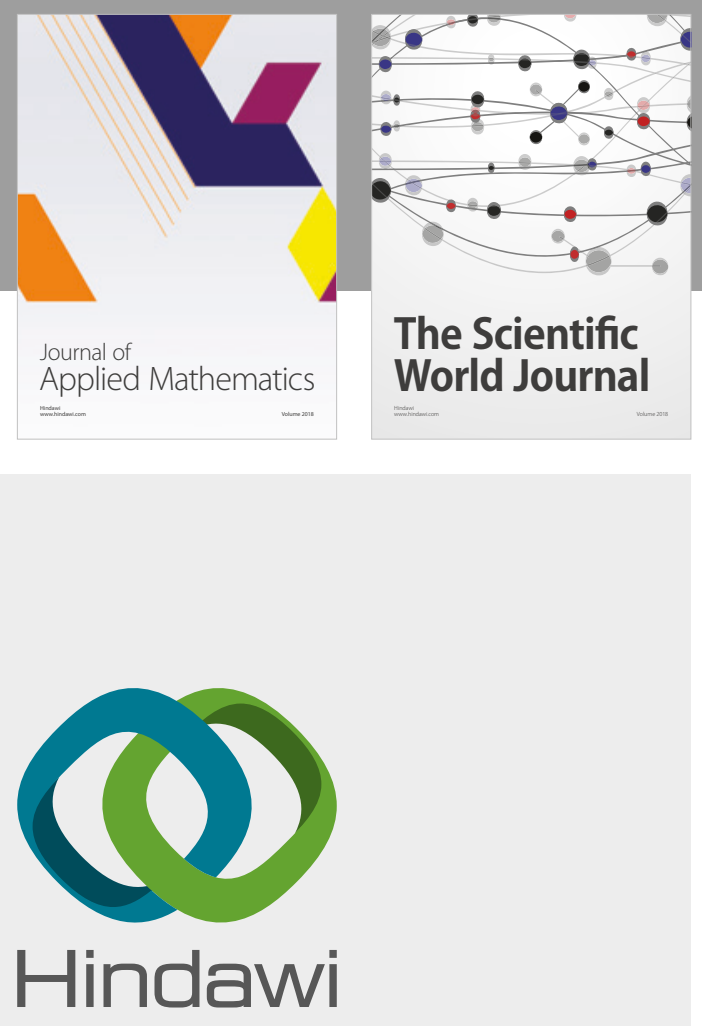

Submit your manuscripts at

www.hindawi.com

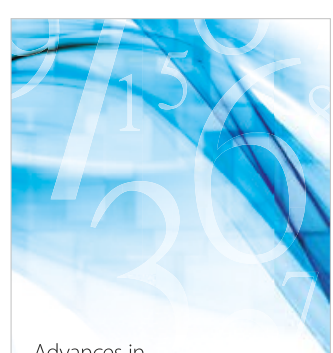

Advances in
Numerical Analysis
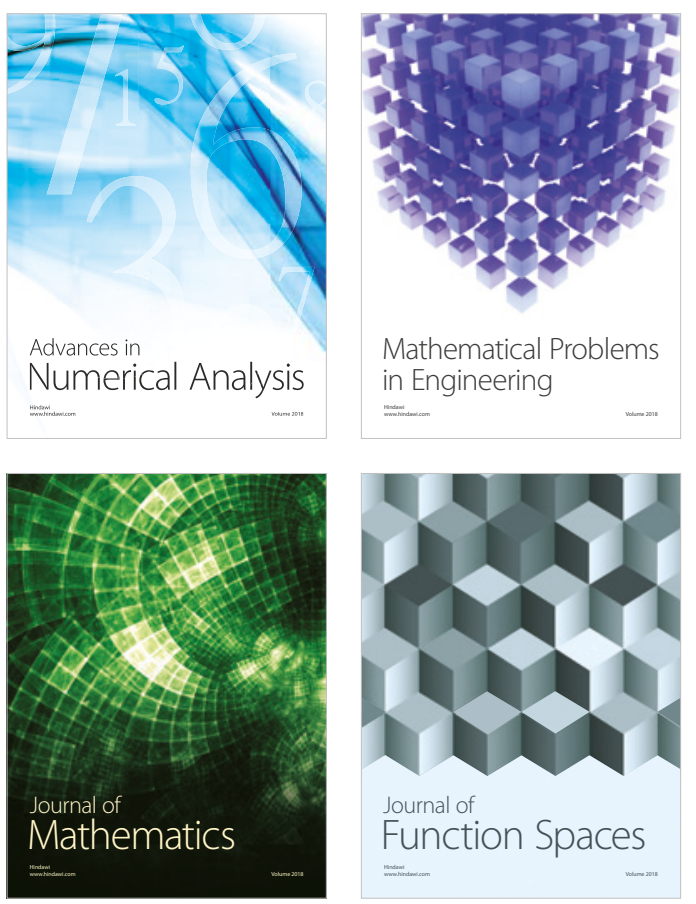

Mathematical Problems in Engineering

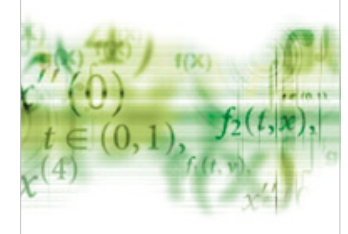

International Journal of

Differential Equations

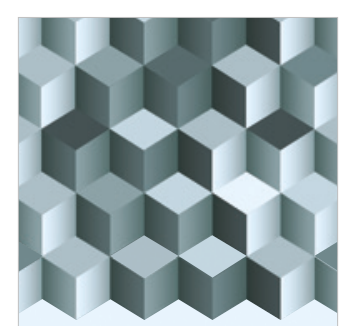

Journal of

Function Spaces

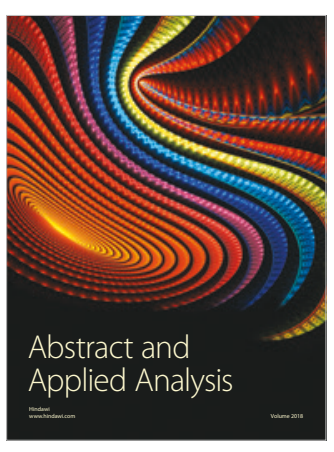

The Scientific

World Journal

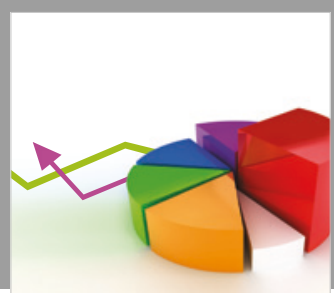

Journal of

Probability and Statistics
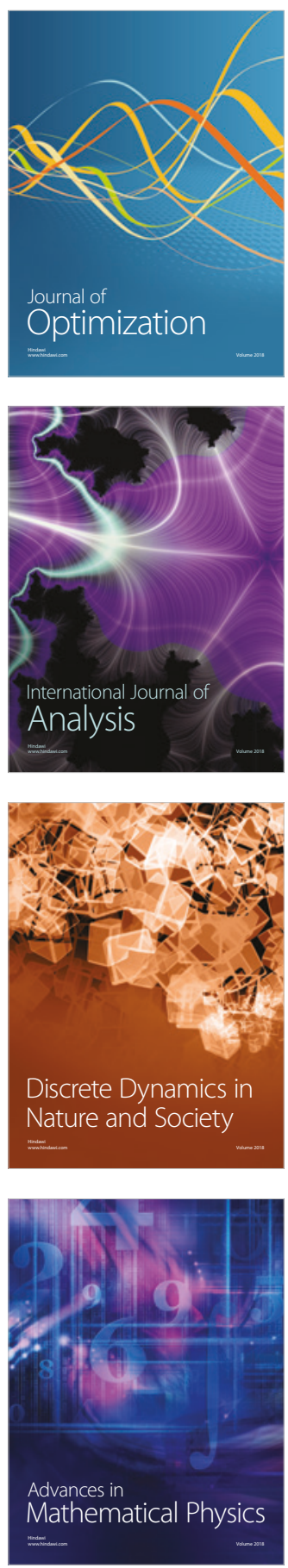